\title{
Preferences for Deferred Losses
}

\author{
J. Frank Yates \\ University of Michigan at Ann Arbor \\ AND \\ ROYCE A. WATTS \\ Rice University
}

\begin{abstract}
The question of whether aversive outcomes are generally preferred at sooner or at later times in the future is examined. Theories predicting choices of advanced and deferred aversive outcomes are summarized. A previous result suggesting overwhelming preference for more immediate aversive outcomes is challenged on the basis of problems endemic to experimental studies of decision making. An experiment that attempted to circumvent those problems is described. Subjects chose between sums of money that could be lost at various times in the future. The subjects were evenly divided in their preferences for advanced and deferred losses. Subjects in a control condition duplicated the results of the previous experiment that had demonstrated the predominance of preferences for advanced aversive outcomes. The implications of the conclusions for a representation of choice over deferred outcomes are discussed.
\end{abstract}

Do people prefer that losses or other misfortunes be experienced in the near or in the more remote future? For instance, given the choice, will the typical individual rather have a lawsuit brought against him in a month or have it postponed for six months? This paper discusses several conditions that might underlie decisions to advance or defer aversive outcomes. It also identifies problems inherent to experimental studies of delay of punishments. Finally, an experiment that attempted to circumvent those problems and answer the original question is described.

Some notational conventions will facilitate the discussion. Borrowing a term from Jamison (1970), let us call a decision alternative offering an outcome $x$ receivable at time interval $t$ from the present a "simple option" $(x, t)$. It is understood that $x$ is receivable immediately or in the future, i.e., $t \geqslant 0$. Let the status quo be represented by the outcome symbol $e$. The binary relations "<" and " $\sim$ ", defined over the set of all

This research was conducted while the senior author was a visiting faculty member in the Psychology Department of Rice University. The advice and critical comments of David Schum and Wesley DuCharme of Rice University and J. E. Keith Smith of the University of Michigan are acknowledged.

Requests for reprints should be addressed to: J. Frank Yates, Department of Psychology, 210C Perry Building, University of Michigan, Ann Arbor, MI 48104. 
pairs of simple options, are to be interpreted as "is less preferred than" and "is indifferent to," respectively. The basic question can be restated compactly as follows. Suppose that for all $t,(x, t)<(e, t)$, i.e., $x$ is "aversive." Suppose further that $0<t_{1}<t_{2}$. Is it the case that for most people $\left(x, t_{1}\right)<\left(x, t_{2}\right),\left(x, t_{2}\right)<\left(x, t_{1}\right)$, or $\left(x, t_{1}\right) \sim\left(x, t_{2}\right)$ ?

As simple as such a question is, previous research on decision making has produced little evidence pertinent to the question either directly or indirectly. Though most theories of decision making are neutral on the matter, almost all empirical studies of decision making have involved "benign" choices. That is, typically, subjects have been required to evaluate or express preferences among options such that the worst that can happen to the subject is that he will leave the experiment empty-handed. (For reviews see Edwards 1954, 1961; Becker \& McClintock, 1967; Rapaport \& Wallsten, 1972). It remains an open and unexamined question whether the dominant decision theories are as descriptive of choices among alternatives involving traumatic consequences as they have been for more pleasant dilemmas.

Most models of decision making tested by experimental psychologists also have not involved the second distinctive feature of the choices of interest here: variable outcome receipt time. Almost universally, subjects have experienced the outcomes of their decisions immediately. Fortunately, related concepts have been at least thought about by psychologists with other primary interests and also by economists. Noteworthy have been studies of the theory of investment and related topics in measurement (e.g., Fisher, 1954; Koopmans, 1960; Fishburn, 1970, Chap. 7; Jamison, 1970), investigations of delayed reinforcement in conditioning (see Renner, 1964, for a review), and studies of propensities to delay gratification (e.g., Davids, 1969; Levine \& Spivack, 1959; Melikan, 1959). A series of studies spawned by the latter tradition provide about the only observational evidence pertaining to the issues of the present study. The experiments of Mischel and his colleagues (e.g., Mischel, 1961a,b,c; Mischel \& Metzner, 1962; Mischel \& Grusec, 1967; Mischel, Grusec, \& Masters, 1969) represent the most extensive and systematic attempt to gain an understanding of preferences for deferred consequences, aversive or otherwise.

No theory, economic or psychological, predicts that people will be indifferent between $\left(x, t_{1}\right)$ and $\left(x, t_{2}\right)$. There are, however, arguments supporting predictions of preferences either way. First, consider an indirect chain of reasoning suggesting that $\left(x, t_{1}\right)<\left(x, t_{2}\right)$, i.e., aversive consequences are preferred later rather than sooner. Mischel and others argue that delay implies uncertainty inherently: ". . . a bird in hand . . ." This unassailable observation is often offered as a partial explanation of the well-documented fact that people generally prefer having good things sooner than later. Classical economic theory (cf. Fisher, 1954) 
offers another plausible explanation for preferences for advancirg the receipt of beneficial consequences, at least money. If one receives a sum of cash today rather than a year from now, if nothing else he could deposit the money in the bank, collect interest, and be $X \%$ richer a year from now than he would be otherwise. In other words, failure to advance receivables represents opportunity costs. Even in some nonmonetary situations an analogous argument for advancing good things can be supported. For instance, receiving recognition for an accomplishment this year rather than next implies that one can reap the benefits of the recognition in the interim and be just that much farther ahead when the year finally rolls around. Koopmans (1960) has identified formal conditions on preference structures that imply the existence of "impatience," a term Fisher (1954) attached to the propensity to prefer the earlier receipt of good things. Symmetric arguments all lead to the conclusion that aversive consequences should be preferred later rather than sooner.

How might preferences for advancing aversive outcomes be explained? Mischel, Grusec, and Masters (1969) offer one rationale. They argue that waiting for aversive consequences is itself aversive. It is as if the person faced with an unpleasant chore concludes, "Well, I might as well get it over with and stop worrying about it." Mischel et al. (1969) report an experiment that seems to support their position that people generally advance aversive outcomes.

It is worth noting that certain conditions in an economy can imply the rationality of preferences for either the immediate or deferred loss of commodities or money. Suppose the exchange value of a commodity is decreasing over time. Or, as in an inflationary economy, suppose the purchasing power of a currency is diminishing with time. In such circumstances the payment of debts should be deferred as long as possible since the true loss represented by the actual goods and services forgone by payment of the debt decreases as time goes on. Precisely the converse holds in a deflationary economy.

Undoubtedly, all the influences suggested by the arguments above affect decisions to advance or defer aversive consequences. The only choice data brought to bear on the question to date, that of Mischel and his associates, lead to the rather surprising conclusion that influences to advance aversive outcomes dominate overwhelmingly. There are reasons to question the meaning of the Mischel results, however. Before considering the problems of interpreting the Mischel experiment, let us describe the essentials of that study.

College student subjects were offered options of participating in electric shock experiments at four different times: immediately, or in 7,14 , or 21 days from the day they were questioned. Conditions were orga- 
nized such that regardless of whether a subject was to receive a shock on a particular day, he was required to be present for other purposes. Thus, there was control for the inconvenience of having to return to the experimental setting. The procedure for recruiting and compensating subjects is particularly significant. The subjects were students in a psychology course who were required to participate in experiments in order to receive full course credit. Hence, at the end of the experiment, i.e., after the shock was administered, each subject was assured that he had at least partially fulfilled his course requirement. Presumably because it involved an unpleasant electric shock, during the experiment subjects were reminded of their option to withdraw from the study. The primary results of the experiment were that when subjects were given the option of receiving shocks at either of two times, they overwhelmingly chose the earlier of the times. There was no correlation between preferences for earlier shocks and scores on the Taylor Manifest Anxiety scale which was also administered to the subjects.

The following argument asserts that the Mischel procedure did not provide a test of the question of whether people prefer aversive consequences either sooner or later. The argument rests on problems involved in inducing subjects to participate in the experiment and the $s u b$ jects' rather than the investigators' perceptions of the choice options offered to them. It will be recalled that an aversive outcome is one that is less desirable than the status quo. The Mischel options very likely did not satisfy that criterion in the subjects' eyes. In order to induce people to serve in experiments they must be offered compensation that will make participation to their net advantage rather than disadvantage. Hence, it is completely reasonable that Mischel's subjects perceived the fulfillment of their course requirement to more than compensate for the promised shock. Otherwise they would have resigned from the experiment. Put another way, their participation in the experiment is sufficient evidence that as far as the subjects were concerned, the effective choice outcome was $x=$ "shock plus fulfillment of course requirement" and not $x=$ "shock." Further, $(e, t)<(x, t)$, for all $t$, i.e., $x$ is not aversive. In this light, it is not at all surprising that the subjects generally preferred the sooner shock. This is merely a replication of numerous findings that beneficial outcomes are preferred at earlier dates. The fact that there was no relationship between anxiety scores and choices of earlier shocks is consistent with the assertion about the subjects' perceptions. If the outcomes are not aversive, there is no reason for anxiety arousal to be a choice factor.

Given the necessity to compensate experimental subjects for their participation, is it possible to test our question experimentally? Yes, and the key to the approach is to separate, at least in the subjects' per- 
ceptions, compensation for participation and the outcomes of choices made in the experiment. The Mischel procedure clearly failed to do this since all compensation was tied explicitly to the decision outcomes at the time choices were made. The strategy of the present study was, in contrast, the following.

Subjects were recruited with the general understanding that they would receive some unspecified monetary reward for participating. They were paid a large base fee prior to the actual experiment. Intervening tasks were arranged to distract attention away from the compensation. Then, options for sums that could be "lost," i.e., amounts to be repaid to the experimenters, at various dates in the future were presented to the subjects. A control condition that simulated the Mischel procedure required subjects to express preferences among options that offered identical net amounts of money as the options in the experimental condition.

Representation of the conditions in terms of simple options should clarify their meaning and their relationship to the Mischel experiment. Let $c$ denote (base) compensation for participating in the study, the present or Mischel's. In this investigation, $c$ is the fee paid to experimental condition subjects prior to the experiment. In the Mischel study, $c$ represents fulfillment of a course requirement. The symbol $x^{\prime}$ represents an aversive outcome presented to the subject. In the Mischel experiment, $x^{\prime}$ represents a shock. In the present study, $x^{\prime}$ is an amount of money $\left(\left|x^{\prime}\right|<c\right)$ the subject could be required to repay or "lose" to the experimenters. In either case, it is assumed that $x^{\prime}$ is aversive, i.e., less preferred than the status quo. The Mischel procedure required subjects to choose among simple options of the form $\left(x, t_{1}\right)$ and $\left(x, t_{2}\right)$, where $x=c+x^{\prime}$ and, as usual, $t_{1}<t_{2}$. In contrast, in the experimental condition of the current study, subjects received their basic compensation $c$ prior to the actual experiment. During the course of the experiment they made choices among simple options of the form $\left(x^{\prime}, t_{1}\right)$ and $\left(x^{\prime}, t_{2}\right)$. In the control condition subjects were required to choose among simple options involving $x=c+x^{\prime}$, as in the Mischel experiment, but with $c$ and $x^{\prime}$ as defined in this study. $x=c+x^{\prime}$ represents amounts actually received by the subjects as their net pay for participation.

\section{METHOD}

\section{Subjects}

Thirty-five female students at Rice University volunteered to serve as paid subjects in the study. The subjects volunteered with the understanding that they would be compensated by some amount of money to be determined precisely during the course of the study. Sixteen of the 
subjects served in the experimental condition, while the remaining 19 subjects participated in the control condition.

\section{Personality Instruments}

Two personality instruments were administered in the experiment. The first device consisted of the course examination part of the Mandler-Sarason Test Anxiety Questionnaire (TAQ) (Mandler \& Cowen, 1958). The second instrument included items from the Multidimensional Internal-External (I-E) Control Scale (Gurin, Gurin, Lao, \& Beattie, 1969).

\section{Stimuli}

The stimuli used in the main part of the study represented pairs of simple options. The simple options had three dimensions: money, payoff time, and probability of payoff. The third factor, uncertainty, was introduced primarily to obscure the purpose of the study and thereby discourage strategies to "outwit" the procedure. Accordingly, only a subset of the pairs of simple options actually presented to subjects are of interest.

Table 1 lists the simple options employed. Consider first the simple options included in the experimental condition. The options consist of the 12 combinations of two amounts of money to be repaid to the experi-

TABLE 1

Parallel Simple Options in the Experimental and Control Conditions

\begin{tabular}{|c|c|c|c|}
\hline Experimental & Control & Experimental & Control \\
\hline $\begin{array}{l}\text { (Amt,. prob., } \\
\text { period) }\end{array}$ & $\begin{array}{l}\text { (Amt., prob., } \\
\text { period) }\end{array}$ & $\begin{array}{l}\text { (Amt., prob., }{ }^{a} \\
\text { period) }\end{array}$ & $\begin{array}{c}\text { (Amt., prob., compl. amt., } \\
\text { period) }\end{array}$ \\
\hline $\begin{array}{r}(-\$ 1,1.0 \\
15 \text { days })\end{array}$ & $\begin{array}{l}(\$ 2,1.0 \\
15 \text { days })\end{array}$ & $\begin{array}{r}(-\$ 1,0.6 \\
15 \text { days })\end{array}$ & $(\$ 2,0.6, \$ 3,15$ days $)$ \\
\hline $\begin{array}{r}(-\$ 1,1.0 \\
35 \text { days })\end{array}$ & $\begin{array}{l}(\$ 2,1.0 \\
35 \text { days })\end{array}$ & $\begin{array}{r}(-\$ 1,0.6 \\
35 \text { days })\end{array}$ & $(\$ 2,0.6, \$ 3,35$ days) \\
\hline $\begin{array}{r}(-\$ 1,1.0 \\
75 \text { days })\end{array}$ & $\begin{array}{l}(\$ 2,1.0 \\
\quad 75 \text { days })\end{array}$ & $\begin{array}{r}(-\$ 1,0.6 \\
75 \text { days })\end{array}$ & $(\$ 2,0.6, \$ 3,75$ days $)$ \\
\hline $\begin{array}{r}(-\$ 2,1.0 \\
15 \text { days })\end{array}$ & $\begin{array}{l}(\$ 1,1.0 \\
15 \text { days })\end{array}$ & $\begin{array}{r}(-\$ 2,0.6 \\
15 \text { days })\end{array}$ & ( $\$ 1,0.6, \$ 3,15$ days) \\
\hline $\begin{array}{r}(-\$ 2,1.0 \\
35 \text { days })\end{array}$ & $\begin{array}{l}(\$ 1,1.0 \\
35 \text { days })\end{array}$ & $\begin{array}{r}(-\$ 2,0.6 \\
35 \text { days })\end{array}$ & $(\$ 1,0.6, \$ 3,35$ days $)$ \\
\hline $\begin{array}{r}(-\$ 2,1.0 \\
75 \text { days })\end{array}$ & $\begin{array}{l}(\$ 1,1.0 \\
\quad 75 \text { days })\end{array}$ & $\begin{array}{r}(-\$ 2,0.6 \\
75 \text { days })\end{array}$ & $(\$ 1,0.6, \$ 3,75$ days $)$ \\
\hline
\end{tabular}

${ }^{a}$ With the complementary probability the subject was required to repay $\$ 0$.

${ }^{b}$ The complementary amount was receivable with the probability complementary to that indicated explicitly. 
menter by the subjects $(-\$ 1,-\$ 2)$, three periods of time until the amounts were to be repaid ( 15 days, 35 days, 75 days), and two probabilities that the amounts would actually have to be repaid $(1.0,0.6)$. The simple options in the control condition columns are "parallel" to the adjacent options in the experimental condition columns. A couple of examples will make clear what is meant by parallel experimental and control condition simple options. A basic participation fee of $\$ 3$ was paid initially to subjects in the experimental condition. Thus, assuming a subject in that condition actually received the simple option $(-\$ 1,1.0,35$ days), her net gain from participating in the experiment would be $\$ 2$. The control condition simple option parallel to that option would offer the same net gain 35 days hence. That is, the parallel simple option is $(\$ 2,1.0,35$ days). The simple option $(\$ 2,0.6, \$ 3,15$ days) in the control condition is parallel to $(-\$ 1,0.6,15$ days) in the experimental condition since both options imply the same expected net value. The former simple option implies that with probability 0.6 in 15 days the owner would be paid $\$ 2$; otherwise she would receive $\$ 3$. The bearer of the latter simple option was paid $\$ 3$ initially and with probability 0.4 would be able to keep it all; with the complementary probability she would be required to return $\$ 1$ in 15 days.

Within each condition 66 distinct pairs of different simple options could be constructed. For obvious reasons, those six pairs consisting of options that differ only in the amounts of money involved were of no interest. Each of the remaining 60 pairs of simple options in each condition were printed on separate response sheets. Care was taken to balance the order of presentation of simple options containing the various probabilities, payoffs, and periods. Probabilities were indicated by partially or completely darkened pie diagrams intended to represent a wheel of fortune that was actually used to determine payoffs. Each sheet contained blanks to allow the subject to indicate her preference between the options described therein. Figure 1 displays two response sheets with the basic format used in the study.

\section{Procedure}

Experimental condition. Subjects were run in groups. Before any experimental procedures were begun, each subject was paid $\$ 3$ for her participation. She was required to sign an official university accounting voucher certifying that she had been paid the amount. Preliminary payment and signing of the vouchers were intended to enhance the impression that the payment was a fait accompli and should have little bearing on the subjects' subsequent behavior in the experiment.

The subjects were then told that the purpose of the study was to examine the effects of value, uncertainty, and time on preferences for 
Please indicate with an " $\mathrm{X}$ " in the appropriate blank the I.O.U. you would prefer to owe to the Psychology Department (you must choose one or the other):

15 days
Pay $\$ 0.00$ $\begin{aligned} & 15 \text { days from now, either pay the Psychology } \\ & \text { if the spinner stops on the dark part of the circt } \\ & \text { it stops on the light part. }\end{aligned}$

Please indicate with an " $X$ " in the appropriate blank the I.O.U. you would prefer receiving from the Psychology Department (you must choose one or the other):

Receive $\$ 1.00+\begin{aligned} & 15 \text { days from now, either receive from the } \\ & \text { Psychology Department } \$ 1.00 \text { if the spinner stops } \\ & \text { on the dark part of the circle or } \$ 3.00 \text { if it } \\ & \text { stops on the light part. }\end{aligned}$
Receive $\$ 3.00$
$\begin{aligned} & 75 \text { days from now, either receive from the } \\ & \text { Receive } \$ 1.00\end{aligned} \quad \begin{aligned} & \text { Psychology Department } \$ 1.00 \text { if the spinner stops } \\ & \text { on the dark part of the circle or } \$ 3.00 \text { if it } \\ & \text { stops on the light part. }\end{aligned}$

FIG. 1. Typical response sheet formats for the experimental (top panel) and control (bottom panel) conditions.

losses. Particular care was taken to emphasize "losses." When they asked, subjects were assured that their eventual losses would not exceed the amount they were paid initially. All further mention of the initial payment was avoided. The subjects were told that the methods to be used for assessing effects of amounts, uncertainty, and time were both "direct and indirect."

The so-called indirect methods consisted of the personality measurement devices the subjects were then required to complete. The primary reason for having the subjects respond to the personality instruments was to further distract attention from the participation fee paid initially. This was the exclusive reason for including the I-E Scale. Assuming that TAQ scores reflect at least partially more general anxiety tendencies, it was thought that they might provide an additional test of the Mischel et al. hypothesis that immediate aversive consequences might be preferred in order to eliminate extended periods of discomfort over impending misfortune.

After the personality instruments were administered the subjects were 
required to choose between the two simple options represented as "I.O.U.'s" on each page of their stimulus booklets. The subjects were cautioned to be very careful in expressing their preferences since their choices would have real implications. They were informed that each pair of simple options was numbered. At the end of the experimental session each subject would have the opportunity to draw a "ticket" from a wellmixed bag of such tickets. The 60 tickets in the bag corresponded to the simple option pairs under current consideration. The subject's requirement to repay money to the Rice psychology department would be prescribed by her response sheet corresponding to the ticket drawn. Of the two simple options represented on the chosen response sheet, she would be required to follow the prescription of the alternative she had previously indicated to be preferred. If the option so indicated involved a probability of 0.6 , the ultimate outcome was determined by the spin of a wheel of fortune with $60 \%$ of its area designated as the losing region.

After all subjects completed their choices among the pairs of simple options, they were allowed to indicate on an open-ended questionnaire any impressions they had of the tasks and their strategies for completing them. The experimenter then allowed each subject to go through the procedure of determining the amount, if any, she would be required to repay to the Rice psychology department at a specified future date. In the event that a subject so incurred a debt, she was required to sign a witnessed statement that she would pay the amount on the required date. The subject was informed that she would be provided through the mail with a self-addressed, stamped envelope to use in remitting the sum on the date it was due.

Control condition. The procedure for the control condition was analogous to that for the experimental condition. The only major distinction concerned the payoff mechanisms. Subjects were not paid in advance. Rather, they were informed that they would receive the amount specified in the simple option chosen by the drawing procedure and, if required, the subsequent spin of the wheel of fortune. The amount would be mailed to them from the Rice psychology department at a time such that, assuming normal postal operations, they would receive their payment on the date implied in their simple option.

\section{RESULTS}

Subjects' choices of primary interest were those between pairs of simple options both with payoff probability 1.0 and equal amounts, but with differing payoff dates. There were six such choices made by each subject. Subjects were classified as "Advancers" if the majority of their choices among those simple options indicated a preference for the option with the sooner payoff date. Those subjects of the opposite persuasion 
TABLE 2

Frequencies of Advanced and Deferred Choices

\begin{tabular}{|c|c|c|c|c|c|c|}
\hline \multirow[b]{2}{*}{ Condition } & \multirow{2}{*}{$\begin{array}{l}\text { Dominant } \\
\text { preference }\end{array}$} & \multirow{2}{*}{$\begin{array}{c}\text { No. } \\
\text { subjects }\end{array}$} & \multicolumn{2}{|c|}{$\begin{array}{l}\text { Constant option } \\
\text { factors }^{a}\end{array}$} & \multicolumn{2}{|c|}{$\begin{array}{l}\text { Frequencies of } \\
\text { choices }\end{array}$} \\
\hline & & & Amt. & Prob. & Adv. & Def. \\
\hline \multirow[t]{8}{*}{ Experimental } & Advanced & 8 & $-\$ 1$ & 1.0 & 23 & 1 \\
\hline & & & $-\$ 2$ & 1.0 & 24 & 0 \\
\hline & & & $-\$ 1$ & 0.6 & 23 & 1 \\
\hline & & & $-\$ 2$ & 0.6 & 24 & 0 \\
\hline & Deferred & 8 & $-\$ 1$ & 1.0 & 0 & 24 \\
\hline & & & $-\$ 2$ & 1.0 & 0 & 24 \\
\hline & & & $-\$ 1$ & 0.6 & 2 & 22 \\
\hline & & & $-\$ 2$ & 0.6 & 1 & 23 \\
\hline \multirow[t]{8}{*}{ Control } & Advanced & 18 & $\$ 2$ & 1.0 & 52 & 2 \\
\hline & & & $\$ 1$ & 1.0 & 53 & 1 \\
\hline & & & $\$ 2, \$ 3$ & 0.6 & 52 & 2 \\
\hline & & & $\$ 1, \$ 3$ & 0.6 & 53 & 1 \\
\hline & Deferred & 1 & $\$ 2$ & 1.0 & 0 & 3 \\
\hline & & & $\$ 1$ & 1.0 & 0 & 3 \\
\hline & & & $\$ 2 . \$ 3$ & 0.6 & 0 & 3 \\
\hline & & & $\$ 1, \$ 3$ & 0.6 & 0 & 3 \\
\hline
\end{tabular}

${ }^{a}$ At each level of constant factors there were three comparisons for each subject, i.e., among simple options with payoff periods of 15 days, 35 days, and 75 days.

were called "Deferrers." As it turned out, there were no subjects who split their choices evenly. Table 2 presents a summary of the choices among those six pairs of simple options made by Advancers and Deferrers in both the experimental and control conditions. Though those preferences do not have direct relevance in the present study, Table 2 also summarizes the choices of the subjects among simple options with constant amounts, differing payoff dates, and payment probability 0.6.

As Table 2 suggests, the subjects within each classification were extremely consistent. In the experimental condition, among the Advancers only 1 deferred choice out of 48 was made; among the Deferrers no advanced choices were made. In the control condition, only 3 of 108 choices made by Advancers were deferred; the lone Deferrer in that condition was perfectly consistent. The difference in the proportions of Advancers and Deferrers in the two conditions is pronounced. The group of subjects in the experimental condition was evenly divided between Advancers (8) and Deferrers (8), while the control condition group was heavily dominated by Advancers (18 of 19). Clearly, whether 
subjects chose among experimental condition simple options or among their control condition parallel simple options led to a difference in tendencies to advance or defer $(p<0.004$, Fisher's exact probability test).

There was no evidence that Advancers in the experimental condition were more anxious than Deferrers. The scores of the two groups of subjects on the TAQ were essentially the same, with Deferrers actually appearing slightly more anxious $(t(14)=-1.967$, n.s.).

\section{DISCUSSION}

The results provide clear evidence against the hypothesis that people overwhelmingly prefer that aversive consequences be experienced sooner rather than later. The preferences of the control condition subjects practically duplicate those obtained by Mischel et al. (1969). This suggests that in Mischel's experiment, as was clearly the case in the control condition of the present study, the subjects did not view their decision outcomes as aversive.

The behavior of subjects in the experimental condition offers direct support for the position that when those outcomes are really perceived as aversive, in a substantial number of instances people will prefer deferred outcomes to more immediate ones. A stronger statement is likely true. There was no difference in net gain offered to subjects in both conditions of the experiment. It could well be the case that for some of the Advancers in the experimental condition the procedures intended to draw their attention from the fact that they would realize a net advantage from participation in the study were unsuccessful. In other words, they might not indeed have separated decision outcomes from participation compensation. The finding that their anxiety scores were not higher than those of Deferrers is not inconsistent with this conclusion. Perhaps in situations in which consequences are more clearly aversive, the Advancers might become Deferrers. Thus, the evidence leans toward the conclusion that aversive outcomes generally are preferred later rather than sooner.

What are the implications of these results? Maybe the present conclusions are applicable only to clear-cut financial choices. Comparisons with situations involving broader aversive consequences such as Michel's electric shock might be inappropriate. That remains, however, to be demonstrated by future research that controls for the type of net compensation problems shown to be operative in the present study and very likely in Mischel's.

As suggested above, a number of factors might contribute to a preference for deferred over immediate aversive outcomes. Certain of those factors are peculiarly operative in monetary transactions. Since the present study involved only monetary outcomes, the generalizability of 
the conclusions to nonfinancial situations may be problematic. In particular, the fact that the national economy was inflationary at the time of the experiment may have contributed significantly to preferences for deferred rather than immediate losses of money. The question of whether or not such a pattern of preference would also hold for losses of constant-value commodities should be investigated directly.

Fishburn (1970, Chapt. 7) has identified conditions sufficient to establish a representation for preferences over what might be called "payoff streams." Payoff streams are merely generalizations of simple options to include outcomes receivable at several rather than single periods in the future. We might denote a payoff stream as follows: $\left(x_{1}, t_{1} ; x_{2}, t_{2} ; \ldots ; x_{n}, t_{n}\right)$, where $x_{1}, x_{2}, \ldots, x_{n}$ are all members of a commodity set $A$. The set of all payoff streams over a set of $n$ periods in the future might be represented by the product set $A^{n}$. Fishburn's theorem asserts the existence of a unique positive number $\pi$ and a continuous real-valued function $\rho$ on $A$, unique up to a positive linear transformation, such that $\left(x_{1}, t_{1} ; x_{2}, t_{2} ; \ldots ; x_{n}, t_{n}\right)<\left(y_{1}, t_{1} ; y_{2}, t_{2} ; \ldots ; y_{n}, t_{n}\right)$ if and only if $\sum_{i=1}^{n} \pi^{i-1} \rho\left(x_{i}\right)<\sum_{i=1}^{n} \pi^{i-1} \rho\left(y_{i}\right)$. When impatience holds $\pi<1$. The critical (and clearly necessary) condition of the representation is independence of the $n$ periods.

The experimental condition of the present study might be viewed as a realization of the circumstances modeled by the Fishburn representation. The compensation $c$ is receivable at $t_{0}=0$, i.e., in the present, while the potential loss $x^{\prime}$ is "receivable" at some later period $t_{1}$ or $t_{2}$ time units away. In other words, the options presented to subjects in that condition might be symbolized by two-period payoff streams $\left(c, t_{0}\right.$; $\left.x^{\prime}, t_{1}\right)$ and $\left(c, t_{0} ; x^{\prime}, t_{2}\right)$. From this perspective the results of this investigation suggest two things. First, since the initial outcomes of each of the payoff streams presented to subjects were identical, if interperiod independence holds, then choices should be determined solely by the outcomes in the periods indexed by $t_{1}$ and $t_{2}$. The point of the extensive efforts to separate initial compensation from subsequent losses was to achieve such independence. The data imply that this attempt was not always successful. Thus, we must conclude that the independence assumption underlying Fishburn's representation can hardly be expected to be satisfied generally, or even often. However, on those occasions when independence can be assumed, perhaps the representation does provide an accurate description of choice behavior over deferred outcomes. The conjecture awaits empirical test.

The second implication of the results of this study in relation to the Fishburn representation concerns uniqueness of the implied value scale. The data of the present investigation suggest, indeed require, that such a 
scale have a unique origin at the status quo. Preferences over deferred periods display a sign-dependency on outcomes (cf. Krantz, Luce, Suppes, \& Tversky, 1971, pp. 329-338). Conditions needed to yield a representation equivalent to Fishburn's, but with a value function unique up to similarity transformations should be explored.

\section{REFERENCES}

Becker, G. M., \& McClintock, G. G. Value: behavioral decision theory. Annual Review of Psychology, 1967, 18, 239-286.

Davids, A. Ego functions in disturbed and normal children: aspiration, inhibition, time estimation, and delayed gratification. Journal of Consulting and Clinical Psychology, $1960,33,61-70$.

Edwards, W. The theory of decision making. Psychological Bulletin, 1954, 51, 370-417.

Edwards, W. Behavioral decision theory. Annual Review of Psychology, 1961, 12, 473-498.

Fishburn, P. C. Utility theory and decision making. New York: Wiley, 1970.

Fisher, I. The theory of interest. New York: Kelley and Mellman, 1954.

Gurin, P., Gurin, G., Lao, R. C., \& Beattie, M. Internal-external control in the motivational dynamics of Negro youth. Journal of Social Issues, 1969, 25, 29-53.

Jamison, D. Studies in individual choice behavior. RAND Memorandum No. P-4255, 1970.

Koopmans, T. C. Stationary ordinal utility and impatience. Econometrica, 1960, 28, 287-309.

Krantz, D. H., Luce, R. D., Suppes, P., \& Tversky, A. Foundations of measurement (Vol. I). New York: Academic Press, 1971.

Levine, M., \& Spivack, G. Incentive, time conception and self-control in a group of emotionally disturbed boys. Journal of Clinical Psychology, 1959, 15, 110-113.

Mandler, G., \& Cowen, J. Test anxiety questionnaires. Journal of Consulting Psychology, $1958,22,228-229$.

Melikan, L. H. Preference for delayed reinforcement: an experimental study among Palestinian refugee children. Journal of Social Psychology, 1959, 50, 81-86.

Mischel, W. Delay of gratification, need for achievement and acquiescence in another culture. Journal of Abnormal and Social Psychology, 1961a, 62, 543-552.

Mischel, W. Father-absence and delay of gratification. Journal of Abnormal and Social Psychology, 1961b, 63, 116-124.

Mischel, W. Preference for delayed reinforcement and social responsibility. Journal of $A b$ normal and Social Psychology, 1961c, 62, 1-7.

Mischel, W., \& Grusec, J. Waiting for rewards and punishments: effects of time and probability on choice. Journal of Personality and Social Psychology, 1967, 5, 24-31.

Mischel, W., Grusec, J., \& Masters, J. C. Effects of expected delay time on the subjective value of rewards and punishments. Journal of Personality and Social Psychology, $1961,11,363-373$.

Mischel, W., \& Metzner, R. Preference for delayed reward as a function of age, intelligence, and length of delay interval. Journal of Abnormal and Social Psychology, $1962,64,425-531$.

Rapoport, A., \& Wallsten, T. S. Individual decision behavior. Annual Review of Psychology, 1972, 23, 131-176.

Renner, K. E. Delay of reinforcement: a historical review. Psychological Bulletin, 1964, 61, 341-361. 